\title{
Towards Empowering Hearing Impaired Students' Skills in Computing and Technology
}

\author{
Nihal Esam Abuzinadah \\ Computer Science Department, Faculty \\ of Computing \\ and Information Technology \\ King Abdulaziz University \\ Jeddah, Saudi Arabia
}

\author{
Areej Abbas Malibari \\ Computer Science Department, Faculty \\ of Computing \\ and Information Technology \\ King Abdulaziz University \\ Jeddah, Saudi Arabia
}

\author{
Paul Krause \\ Department of Computing \\ University of Surrey \\ Guildford, United Kingdom
}

\begin{abstract}
Studies have shown that deaf and hearing-impaired students have many difficulties in learning applied disciplines such as Medicine, Engineering, and Computer Programming. This study aims to investigate the readiness of deaf students to pursue higher education in applied sciences, more specifically in computer science. This involves investigating their capabilities in computer skills and applications. Computer programming is an integral component in the technological field that can facilitate the development of further scientific advances. Devising a manner of teaching the deaf and hearing-impaired population will give them an opportunity to contribute to the technology sector. This would allow these students to join the scientific world when otherwise; they are generally unable to participate because of the limitations they encounter. The study showed that deaf students in Jeddah are eager to continue their higher education and that a large percentage of these students are keen on studying computer science, particularly if they are provided with the right tools.
\end{abstract}

Keywords-computer programming education; deaf; hearingimpaired students; e-learning

\section{INTRODUCTION}

With the rapid advances made in the field of educational technology, it is reasonable to expect that physical disabilities such as hearing impairment are no longer barriers to acquire higher education. However, deaf and hearing-impaired students may face many obstacles during the learning process due to their disabilities; they may experience isolation, low self-esteem, and learning difficulties[1]. According to the World Federation of the Deaf (WFD), there are over 352 million deaf people in the world, many of who are either deaf from birth or became deaf before learning the spoken language. This is a significant challenge to the education of deaf people. More than $80 \%$ of deaf people lack education or are undereducated because they are not provided with the necessary supporting learning facilities 1 . The Salamanca conference - concerning the state of special needs education places a great on all governments to consider all learners with disabilities. The conference sponsored by UNESCO, recommended that educational regulations should account for differences among learners.
Hearing disabilities should not be viewed as barriers to academic achievement, especially with the rapid advances in educational technology. Although the number of deaf students attending universities and colleges has increased lately, several studies have shown that most deaf students do not complete their higher studies because of several difficulties [2]. These difficulties range from the inability to hear either partially or wholly, to the lack of special facilities to aid them in overcoming the personal and social barriers they encounter due to hearing deficiency or loss or at least enable them to advance their learning proficiency as fast as their peers [3]. Therefore, effective technological support is essential to enhance the learning environment of deaf and hearingimpaired learners. The failure of educational institutions, and the community at large, to offer deaf students with the adequate support that they require to overcome their physical limitations, is an unfortunate circumstance to the great disadvantage of deaf and hard-of-hearing students.

\section{BACKGROUND}

In most developing countries, one of the main challenges preventing hard-of-hearing and deaf students from getting the higher education that will equip them to support themselves economically is the absence of accurate and reliable data on the size, kinds, and causes of deafness in the region. In Saudi Arabia, only when the deaf student finishes secondary education and wants to enroll into university program do the authorities of higher educational centers get a glimpse of the needs of those learners. In the year 2011 deaf students were accepted in the Saudi Universities; 20 students were registered at King Saud University, which was the first university in Saudi Arabia to accept deaf students among hearing students ${ }^{2}$. This shows that the number of deaf and hard-of-hearing persons accessing higher educational facilities still remains quite low. Scientific research on the best ways to teach deaf students through virtual learning is imperative towards increasing the literacy level in this population within Saudi Arabia. This necessitates research to determine the best strategies to enhance the continuing of professional education within the tertiary institutions by the deaf and hard of hearing persons. This study aims to test the ability of deaf students to study and understand a highly technical subject such as

\footnotetext{
2 University, K.S. University mission press. 2011; Available from: http://rs.ksu.edu.sa/55403.html.
}

\footnotetext{
${ }^{1}$ Deaf, W.W.F.o.t. Who Are We? - WFD | World Federation Of The Deaf. 2015; Available from: http://wfdeaf.org/whoarewe.
} 
computer programming and challenge the widespread perception that the deaf cannot learn complex subjects[4]. The deaf have a hidden potential that can only be tapped through the proper exploitation of available research tools by ambitious scholars[4]. Despite the high number of studies aimed at developing feasible solutions as higher education aids for deaf students and the recognition of the paucity of deaf students acquiring higher education, only a limited number of these approaches have been developed thus far, especially for teaching certain complex subjects such as Computer Science and Programming[5]. In particular, efforts towards the development of tools to enable students with hearing disabilities access technical courses such as computer science have been far from adequate[6]. However, it is important to acknowledge that some of those deaf students may be very gifted, bordering on talented in the field, but they do not receive proper exposure and opportunities to demonstrate this in the classroom.

In many developing countries, deaf students are deprived of the opportunity to pursue higher education[7]. For instance, in Saudi Arabia, it is very rare to find a deaf student in the universities, especially in the fields of applied sciences or nontheoretical specialties. Moreover, currently, many Saudi universities use live interpretation to teach deaf students; this method has many disadvantages, including the interpreter's lack of subject knowledge and the cost of hiring an individual interpreter[8].

E-Learning, content visualization, virtual reality, and mixed reality are promising technologies that might facilitate the provision of accessible higher education courses for deaf and hearing-impaired students. Digital environments provide deaf persons platforms to enhance learning by using technology that facilitates the acquiring of information without necessarily having to use the sense of hearing. There is a need to develop new ways of propelling learning and making it readily available even to disadvantaged students. In this regard, the aim of technological intervention is to make work easier, irrespective of the time and cost involved. As an important concern to all world economies, education needs to be provided equally to all students, even if they have hearing impaired. Thus far, sign language, as opposed to technology, has always been the mainstay in imparting education to deaf persons.

\section{LITERATURE REVIEW}

\section{Definition of deaf and hearing impaired}

The term "deaf" is often used to refer to persons with severe hearing loss without the use of assistive devices. The term "hearing impaired" is generally used to refer to persons with significant hearing loss ${ }^{3}$.

According to Wareham et al., there are different categories of deaf people, ranging from hard-of-hearing to deaf passing throughout partially deaf, deafened and deaf [9].

\footnotetext{
${ }^{3}$ Washington.edu. How are the terms deaf, deafened, hard of hearing, and hearing impaired typically used? . 2015; Available from:

http://www.washington.edu/doit/how-are-terms-deaf-deafened-hard-hearingand-hearing-impaired-typically-used.
}

TABLE I. DEFINITION OF DEAF

\begin{tabular}{|l|l|}
\hline Term & Definition \\
\hline $\begin{array}{l}\text { Deaf with a } \\
\text { capital D }\end{array}$ & $\begin{array}{l}\text { Persons with severe to profound deafness who regard } \\
\text { themselves as belonging to a culture and linguistic } \\
\text { minority; they are most likely born deaf or became deaf } \\
\text { in infancy }\end{array}$ \\
\hline $\begin{array}{l}\text { Deaf with a } \\
\text { lower-case d }\end{array}$ & $\begin{array}{l}\text { Persons with the same situation but can speak and lip } \\
\text { read }\end{array}$ \\
\hline Deafened & Persons who lost their hearing after maturity \\
\hline Partially deaf & Persons with moderate to severe hearing loss \\
\hline Hard of Hearing & Those with mild to moderate hearing loss \\
\hline
\end{tabular}

Deaf and hearing impaired in Saudi Arabia

Disabling hearing loss simply refers to the hearing loss that is above 40 decibel (dB) for the better-hearing ear of adult human beings and over 30 in children aged between 0 to 14 years. The World Health Organization (WHO) released the definition of magnitudes that cause hearing loss in the year 2012 based on the findings of about 42 population studies. These studies also established the prevalence of hearing loss among populations from Latin America, sub-Saharan Africa, Europe, and Middle East[10]. These investigations show that the $\mathrm{dB}$ limit for many patients with hearing loss is high, which is reflected in the high prevalence of hearing loss worldwide.

The national statistics provided by the National Center for Health Statistics in the United states of America indicate that the number of deaf persons worldwide is increasing and that there are 22 million deaf and 36 million hearing-impaired persons in the world [11]. According to the latest fact sheet of the WHO released on March 2015, more than 5\% of the world's population, i.e., 360 million people, have hearing loss (328 million adults and 32 million children) ${ }^{4}$. According to a survey conducted on 9540 Saudi children in Saudi Arabia (2002), 1241 (13\%) had hearing Impairment and 782 (8\%) were at risk of hearing impairment[12]. Further, a study conducted by Brelje H. William from the Gallaudet University Library showed that in Saudi Arabia, the number of only children with hearing impairment was about 2526 since no accurate numbers were available for adults[13]. On the other hand, a Global Survey Report WFD Interim Regional Secretariat for the Arab Region published in 2008 stated that there are 100,000 deaf persons in Saudi Arabia[14].

The number of persons identified as being deaf or hearing impaired is not exhaustive in both the studies and statistics. Several reasons can be possible for this, including the reluctance of parents to state that their children have hearing impairment.

\section{Higher education for deaf students}

Although higher education for the deaf students is an important concern in Saudi Arabia. Saudi Arabia has 24 public universities, one e-university, 8 private universities, and 21 private colleges all over the country ${ }^{5}[15]$. However only less than $0.03 \%$ of the deaf graduated from the deaf high schools affiliated to Saudi Universities and almost zero percent are

\footnotetext{
${ }^{4}$ Who.int. WHO | Deafness and hearing loss. 2015 11-05-2015]; Available from: http://www.who.int/mediacentre/factsheets/fs300/en/.

5 Education, S.M.o. Education Statistic System. 2015; Available from: https://hesc.mohe.gov.sa/pages/default.aspx
} 
from colleges of applied sciences such as computer science. We surveyed the data from all the public universities for the duration between January 2014 and March 2014 to determine the number of deaf students enrolled and the teaching methods used to facilitate learning for these students. Most universities do not offer some courses for deaf and hearing impaired persons.

In Saudi Arabia, several measures to enable deaf people complete educational programs have been introduced by various universities, such as King Saud University. King Saud University has implemented adequate learning and hearing facilities to allow deaf students to complete their courses without much difficultly.

The first two institutes for the deaf were established in 1964 in Riyadh, one for boys and another for girls. All education is under the auspices of the state, which provides free education for all at all levels to both citizens and residents[16]. Children with hearing loss of over $50 \mathrm{db}$ and IQ greater than 70 are qualified to attend one of the residential schools for the deaf. Otherwise, the child is allowed to continue mainstream education with an emphasis on speech training. In 2007, there were more than nine residential schools for the deaf in Saudi Arabia[17].

In United States of America, Gallaudet University is a university specifically established for deaf and hard of hearing students, where the undergraduate enrollment for the year 2014 was 1031, including both full and part-time students and more than 19000 students graduating in different majors ${ }^{6}$. This university offers courses with Information Technology (IT) major for deaf students. The University claims that its IT program provides a high-quality educational experience in IT to undergraduate students in a bilingual environment. Although Gallaudet is the only university in the world for deaf students, many other universities worldwide accept deaf students; most of them offer live interpreters to facilitate the different courses. One such facility is the Rochester Institute of Technology, which has nine different colleges, including the National Technical Institute for the Deaf, Rochester, New York (NTID). This Institute has more than 15,000 undergraduate students on campus, with 1,200 being deaf or hard of hearing; instructors at the institute use various communication methods, including American sign language (ASL), spoken language, finger spelling, printed and visual aids, and online resources. In addition, FM systems have been made available along with tutoring, note-taking, real-time captioning services, and interpreting $\operatorname{staff}^{7}$.

Another institution, the Doncaster College for the Deaf, Doncaster, South Yorkshire, United Kingdom, specializes in catering to students who are deaf or hearing impaired, as well as those with Autism and Asperger. They provide vocational training in nine industries to students aged 16 years and above. Students are taught style of "total communication," which is a form of instruction that encompasses a variety of

\footnotetext{
${ }^{6}$ University, G. Fast Facts - Gallaudet University. 2015; Available from: https://www.gallaudet.edu/about-gallaudet/fast-facts.html.

${ }^{7}$ Ntid.rit.edu. RIT - NTID - Overview. 2015; Available from:

http://www.ntid.rit.edu/about
}

communication systems including sign, oral, auditory, written, and visual aids ${ }^{8}$.

The National University Corporation of Tsukuba University of Technology (NTUT) in Japan is the only higher educational institute for hearing impaired and visually impaired students. As of 2010, 373 students were enrolled at the institute, with 7 graduated students; the University has Computer Science courses, but these cater mainly to visually impaired students. The institute provides various services for deaf students such as SL guidance; various visual aid presentations; summary notes for lessons by part-time lecturers; and, supplementary lessons to individuals in subjects in which academic achievement can be difficult, such as foreign languages or math and science ${ }^{9}$.

\section{Communicating with the deaf}

While people generally use hand gestures for communication in addition to the spoken language, deaf persons depend heavily on hand gestures as a way of communication. Sign language (SL) is different from spoken languages; it involves the use of body gestures instead of voice and is received through the eyes rather than the ears. SL is the basic communication method for deaf and hearingimpaired people who rely on it to communicate their thoughts with others using hand gestures along with some body movements and facial expressions[18].

The wide range of cultures of deaf people from all parts of the world has led to the evolution of signing to form complete and sophisticated languages. Like there are grammar and usage rules for all spoken language, sign language also has its own regulations and rules. Further, SL differs from one country to another and also in different parts of the same country[19].

Generally, deaf people do not face many issues when using their common SL to communicate. However, the difficulties arise when deaf persons attempt to communicate with nondeaf persons, especially those who do not understand SL; this usually leads to frustration[20]. Thus, there is a barrier to the communication between both parties, which can result in misunderstandings and hinder effective communication.

\section{Arabic Sign Language}

Several efforts have been made to establish the SL for use in Arab countries. Such efforts have led to the development of many versions of SL, almost as many as the number of Arabic-speaking countries, owing to the varying heritage, culture and dialect with country; however, the same sign alphabets are used[21]. Since the Arab world has a very similar culture, heritage and sign alphabets, efforts are in progress to unify Arabic SL. In 2001, the League of Arab States, in a joint effort with the Arab league Educational, Cultural and Scientific Organization, released the first unified dictionary where the first version contained 1000 words.

\footnotetext{
8 .Deaf-trust.co.uk. About : Communication Specialist College. 2015; Available from: http://www.deaf-trust.co.uk/college/about/

${ }^{9}$ Tsukuba-tech.ac.jp. National University Corporation Tsukuba University of Technology | ABOUT. 2015; Available from: http://www.tsukubatech.ac.jp/english/about/.
} 
Another version of this dictionary was issued in 2007 with 600 additional words, making a total of 1600 words[17].

\section{Sign language recognition}

To bridge the communication gap between deaf and nondeaf persons, translators or interpreters are always necessary. These interpreters and translators are human; however, with growing interest among the scientific and research community towards helping deaf persons and the development of technology, a few applications and tools have been developed to help deaf improve their hearing world and simplify their ability to communicate[22]. Efforts have been made to automate the translation of the gestures to text or spoken language and vice versa, initially with the use of images of signs and then with video clips and files[23]. Threedimensional images and avatars are the latest tools in this field. The following table shows a comparison between the use of videos and avatars for deaf/non-deaf interpretation of SL:

TABLE II. USE OF VIDEOS AND AVATARS

\begin{tabular}{|l|l|l|}
\hline $\begin{array}{l}\text { The speed of } \\
\text { signing }\end{array}$ & Can be controlled & $\begin{array}{l}\text { Videos } \\
\text { person's speed }\end{array}$ \\
\hline $\begin{array}{l}\text { Seeing the signs } \\
\text { from different } \\
\text { angles }\end{array}$ & $\begin{array}{l}\text { Signs can be viewed } \\
\text { from different angles }\end{array}$ & One stable angle \\
\hline The file size & $\begin{array}{l}\text { Small, measured in } \\
\text { KB }\end{array}$ & Large, measured in MB \\
\hline Effects to website & $\begin{array}{l}\text { Easley uploaded due } \\
\text { to its small size }\end{array}$ & $\begin{array}{l}\text { Takes longer time to be } \\
\text { uploaded }\end{array}$ \\
\hline
\end{tabular}

Videos are not the same as avatars and are not functionally the same with respect to teaching deaf persons. Table 2 compares avatars and videos with respect to different functional aspects: speed of signing, angle of signs as viewed by the user, file size that they can hold, and effects that they can contribute towards the website in terms of the time taken to upload, depending on the size of files.

Cooper et al. studied the key aspects of SL recognition (SLR), aiming to develop algorithms and methods to correctly identify a sequence of produced signs and decipher their meaning. They explored the types of data available and their merits and classified and discussed the manual aspects of the signs from both tracking and non-tracking viewpoints. Their methods of combined classification of signs helped the further development of SLR techniques[24].

In 2001, Aljarra and Halwani attempted to develop a system for the automatic translation of gestures of the manual alphabets in the Arabic SL. They designed a collection of adaptive neuro-fuzzy inference system (ANFIS) networks, which deals with images of bare hands that are then processed and converted into a set of features that comprises the length of some vectors. Using the hybrid-learning algorithm in training and the subtractive clustering algorithm, they constructed the fuzzy inference systembased on the leastsquares estimator. Subsequent experiments revealed that their system could recognize 30 Arabic manual alphabets with an accuracy of 93.55\%. Subsequently, in 2008, Halawani introduced the Arabic Sign Language Translation Systems (ArSL-TS) that runs on mobile devices[25]; this system was found to be effective, although its full implementation was not enhanced.

\section{Avatars and sign language recognition}

Researchers in the field of computer science have taken several steps towards the development of software tools and applications to improve the lifestyle of deaf and hearingimpaired persons. One such development is the creation of avatars, which has further paved the way for many computer applications that allow featuring signs and displaying them. Most of these applications are not linked to a specific SL, which allows for the development and display of signs in different sign languages[26].

In most cases, the interpretation of applications requires two tools: the gesture builder and image player. Using the gesture builder, the figures can be animated and made to change their position to show the signs according to the human signal performance. The signal coordinates are then saved in a small text file that represents the sign and displays it subsequently; this file is then sent to the player who displays it through the avatar in a manner similar to the human way[2].

Some of the applications used to generate and display signs are discussed below. Vcommunicator ${ }^{10}$ is a software developed by Vcom3D that includes a gesture builder, which allows the user to build the signs by selecting the appropriate hand movement and facial expression from the pre-saved images in the system. This commercial tool supports only American Sign Language (ASL).

Another application is the Sign Smith Studio, which allows the users to display the signs using the gesture builder $^{11}$. The advantages of this software are its clear, userfriendly graphical interface; ability to connect with other applications; and vast database of ready-to-use signs. However, despite these advantages, the system does have some critical disadvantages, the most important of them being the inability to use it in internet applications. Other disadvantages are that the hand positions in this system can only be chosen from the pre-saved images, without any modifications and the files will be exported and saved as video files. These disadvantages make the system quite unreliable and inefficient.

The eSign is a project funded under the Information Society Technologies (IST) program of the European Union's Fifth Framework and supported by the eContent program ${ }^{12}$. Under this project, several software tools have been developed that allow website and other software developers to augment their applications with signed versions. This software consists of an eSign editor that is used to build the signs, and the files developed are saved in the SEGML format. It also contains the eSign player with a tool that displays the pre-built signs. The advantages of this software are that the avatar motions are very realistic, can also include facial expressions, can be used

\footnotetext{
${ }^{10}$ Theard, J.J. and Vcom3d.com. Vcommunicator. 2015; Available from: http://www.vcom3d.com/vcommunicator.php.

${ }^{11}$ Theard, J.J. and I. Vcom3D. Sign Smith. Vcom3d.com 2015; Available from: http://www.vcom3d.com/signsmith.php.

12 Visicast.cmp.uea.ac.uk. eSIGN at UEA. 2015; Available from:
} http://www.visicast.cmp.uea.ac.uk/eSIGN/ 
to display long sentences in signs, and allow viewing from different angles. However, a critical disadvantage of the avatar is the need for prior knowledge of the coding system for the development of the signs using the editor.

Elghoul introduced a specialized Learning Content Management System (LCMS) that incorporates multimedia courses to teach and learn SL. This system allows teachers to create courses for deaf students without the need to learn SL. It uses Websign, a web-based interpreter of SL developed for this program, which permits the automatic interpretation of written text into visual gestured spatial language by using avatar technology[27].

Another Arabic effort is TAWASOUL program, which is a master project to teach Arabic Sign Language (ArSL); it uses the Vcommunicator system to create and generate the signs and then transform them into video files and integrate them in the program[28]. This is a disadvantage since it does not allow the user to control the speed of the sign. Moreover, some of the signs may not be very clear since all signs are displayed from the same angle.

\section{Teaching computer science and programming to the deaf}

In the light of the current advances in software technology, it may be hoped that the teaching of computer science and programming will open new opportunities for this group of students. The use of eLearning resources specially built for the deaf and hard-of-hearing students in Saudi Arabia, particularly those enrolled in higher institutions of learning, will help improve the quality of education services provided to these students. Deaf students often struggle to pursue education in technical fields such as Computer Science (CS). If facilities are available, course instruction is traditionally presented as "mediated instruction"[29], involving the use of sign language interpreters. However, all interpreters cannot be expected to possess the content knowledge required to convert instructions in regular classes such that they can provide deaf students with content information, which can easily be obtained by their hearing peers[30]. Therefore, it may be reasonable to assume that the proper use of avatars in order to teach computer programming will enhance smoothen the education process for deaf learners seeking to learn computer programming. Several studies have been undertaken towards the use of Information and Communication Technologies (ICT) integration systems in enhancing effective learning for the deaf and hard of hearing, ICT is defined as a "diverse set of technological tools and resources used to communicate, and to create, disseminate, store, and manage information” [31, 32]. An investigation by Kulik and his counterparts revealed that the students with special needs who use ICT in learning actually require only a small amount of time for learning as compared to when they use the traditional manual learning systems[33].

\section{E-learning environment for learning programming languages}

The designing of a curriculum to facilitate learning about computer technology for the deaf to learn is a challenging but rewarding prospect. Deaf and hearing-impaired students have issues only with their hearing capacity, but have good visionary ability and can always find a way to best understand a programming language[34]. Therefore, there is a definite need for the development of effective and user-friendly technologically advanced systems learning system that will help them complete their educational requirements in this field. Avatars can help establish a viable e-learning environment for deaf and hard-of-hearing students. An avatar has the qualities of a tutor, but with the integration of modern technological considerations, it can be made more interesting with its expression learning [27].

This investigation seeks to test the readiness of deaf people in Saudi Arabia and their willingness to study computer programming. Further, the research attempts to examine the best methods to instruct and promote learning among deaf and hearing-impaired persons. The subsequent sections of the research include the Literature review of published data relevant to the research question. This is important since it will help in unfolding the critical issues in this research. Further, the Motivation and problem statement section seeks to highlight the issues that contributed to choosing the research topic, while the Methodology section provides information on how the research was conducted. The findings of the study are provided in the Results section and discussed in the Conclusion. The Conclusion will give a summary of the research findings.

Most deaf students in Saudi Arabia cannot pursue study in institutions offering higher education; this is quite discouraging[25], particularly in the light of the rapid advances in technology. Hearing disabilities, whether full or partial, affect large segments of the population in any country. Therefore, failure to educate such a disadvantaged population would result in a high percentage of illiteracy. This research topic is important because it seeks to find solutions to combat the lack of education, especially at the higher professional levels among deaf students. This is particularly important in the computer science and programming fields since these are integral and significant in the current world in terms of their contribution to the job market.

Previous investigations aiming at devising new methods of learning have been carried out by different scholars. Various papers have been published by various scholars to guide the inquiry of the avatar tool for the teaching of computer programming. Both recent and past studies have attempted to devise explicit ways of dealing with the challenges posed in the education of deaf and hearing-impaired students. The available literature, therefore, serves as a solid background for informing the current inquiry and providing insight into the devising of the avatar-teaching tool for the study of computer programming.

The three elements that the researchers have focused upon in the Literature review section in order to gain an insight into the relevant information available include Students, Available tools, and Program material.

Students (Understand cognitive perception of students with severe hearing problem)

Research on the learning styles of deaf students has highlighted the concepts of field dependence/independence 
and reflectivity/impulsivity. Studies have employed personality-type measures and social interaction approaches and found that deaf students, as a group, appear to have a more field-dependent cognitive style than their hearing peers[35].

Further, a study conducted for the National Technical Institute for the Deaf in Rochester Institute of technology, examined six learning styles of the Grasha-Riechmann student Learning Style Scale (GRSLSS) in a study on 100 deaf college students. The students' mean scores were higher for the dependent, participative, collaborative, and independent dimensions than for the competitive and avoidant style. Thus, the study suggested that deaf college students preferred certain learning styles more than others and that these preferences were related to the level of students' academic achievement, to their motivation, and to the manner in which they used course resources[36].

Another interesting finding was the impact of deaf students' families, which was found to be important and effective in a Taiwanese study examining the relations between academic performance and the variables of age, gender, degree of hearing loss, primary communication modes, amplification, high school educational experience, and family relationship in deaf and hard-of-hearing college students. Research has shown that factors associated with student academic success are numerous, including demographic, aptitude, communication, and audiological characteristics[37]. Thus, family relationship was found to play a unique and significant role in predicting academic success, suggesting that college students in Taiwan who reported having more problems in the area of family relationship were more likely to experience academic difficulties and have lower GPA scores[35].

Another study sought to compare thinking styles and university self-efficiency among deaf, hard-of-hearing, and hearing students. The study used the Thinking Styles Inventory-Revised II and the University Self-Efficiency Scale on 366 deaf and hard-of-hearing and 467 hearing university students in mainland China and found that participants with Type 1 styles (i.e., more creativity-generating, less structured, and cognitively more complex) had higher levels of university self-efficiency. The study also showed that deaf and hard-of hearing students with Type 2 styles (i.e., more norm favouring, more structured, and cognitively more simplistic) had lower levels of university self-efficiency[38]. However, the study had some limitations, since the deaf students enrolled in this study were university students who had attended secondary schools for the deaf and the results cannot be generalized to deaf students attending school along with hearing students; further, the selected participants belonged to the same academic discipline (art and design majors). In addition, senior students majoring in SL, rather than professional or more experienced SL interpreters, were employed in the administration of the inventories to the enrolled students, which may have influenced the results of the research.

Available tools and avatar-based approaches to teach deaf
A LMS that offers German Sign Language videos in correspondence to every text in the learning environment was presented in 2004. The ALIB system was designed for deaf adults who wished to improve and maintain both their mathematical and reading/writing skills. Nevertheless, most of the German deaf adults did not receive school education in SL and, therefore, they lacked basic reading and mathematical skills necessary for further vocational training. The low reading skills also restrict their possibilities of information gathering and self-directed learning. In the light of these findings, a LMS is adapted to the needs of deaf people, with SL videos for each text block as the most important feature[39].

Another group of German computer scientists from Saarbrücken in Germany developed an online avatar that displays online content in SL. They collaborated with Peter Schaar, who is deaf and is a lecturer for SL at the Saarland University Language Center and the College of Engineering and Commerce in Saarbrücken[40]. However, their approach was to make online content accessible to the deaf, and not develop a tool directed to teach deaf students.

The need to increase the effectiveness of the ArSL system and apply it to teaching deaf students via interactive media was addressed in a study conducted in King Abdulaziz University in 2013. It showed that there is a growing need for an avatar-based natural Arabic SL system for deaf people; their key challenge has been the realization of a clear and natural gesture language by using computer animation[41]. However, their system was unable to represent SL in 3-D animation technology for the education of the deaf, with fluidity and realism to enhance self-image rather than being emotionally inhibiting. Moreover, the study targeted deaf children in the primary education years and the researchers have only reached the design level.

In 2013, a study was conducted to incorporate SL and spoken language skills as bilingual programs adapted from the hearing population model. Of particular interest in this study was the nature of visual communication in relation to meaning, memory, and identity. The study combined bilingual, visual, and an interactive multi-media learning environment (tool) to improve the individual performance of deaf children. One mode uses text graphics to read Thai language by signs and with pictures, while a second mode recognizes meaning from SL and pictures. With this program, deaf individuals can learn Thai written language and Thai SL at the same time. The researchers found that deaf individuals can learn to read using the SL picture story technique. The context of the story can be perceived through the text meaning and help children learn another language through picture and SL. The researchers studied deaf children aged 10-13 years and indeed found that the children could simultaneously learn both Thai written language and Thai SL at the same time[42].

One of the older attempts was EVIDENT. The main goal of EVIDENT was to develop an interactive educational software that can be used in a bilingual educational setting and which is not restricted to any particular SL. The final product of EVIDENT was a CD-ROM containing information both in sign language (Swedish, Dutch, Greek, and British SLs) and in 
written/spoken language (Swedish, Dutch, Greek, English) about a specific topic[39].

Another CD-ROM project is the SMILE project, which created a prototype language course application delivered on CD-ROM during the course of the research. Various other modes of delivery have also been under consideration, including online delivery. Accompanying this prototype version, a general platform was being developed in order to allow easy and straightforward implementation of the learning materials in different European languages[42].

A research group in Duplin working on Human-Computer interaction (HCI) released in 2010 on human-like avatars for SL synthesis and proposed to advance HCI by improving avatar quality and realism with a view to ameliorating communication and computer interaction for the deaf community. They proposed to collaborate with the team at University of East Angalia (UEA) in the development of their system by providing more linguistic data to the baseline system as part of a wider localization project[43].

Many other efforts have been made in the field of speech to SL recognition by using avatars. In 2012, a team in King Abdulaziz University proposed an avatar-based translation system from Arabic speech to Arabic sign language for deaf people. Their proposed system is composed of a database of captured 3D motions of the Arabic SL. The SL motion was recorded using data gloves. A graphical translation of the digitized SL is re-animated using standard techniques. Common spoken words are directly translated into respective semantic using Sphinx-4 Speech Recognition Engine without first being translated into text. Using the same Sphinx-4 Engine, the semantic of the spoken Arabic language is translated into ArSL[44]. This system is still in its early developmental phase and the team did not implement it.

The project Signing Books for the deaf explored how information should be presented to deaf people on video, where the sign presenter should be located on screen, what the most suitable camera set-ups are, and how should subtitles be used $^{13}$.

The Classroom of the Sea (COS) Project is an interactive problem-based learning environment embedded in marine science. The system was tested on deaf students in high school in order to assist them in understanding and communicating scientific concepts. This system involved the use of a mixed reality environment for students and teachers aboard a research vessel and guided them as they gathered marine science data required to address a specific problem. The students were asked to record the locations of their samples on the ship's LAN and, subsequently, from their classrooms, they entered the data they collected onto web sites along with the faculty and researchers, thereby enabling the students to experiment with real data, generate hypotheses, test these hypotheses, and prepare write-ups of their findings. Changes in the knowledge, attitudes, and behaviors (KABs) of the students were measured and data regarding self-efficiency

${ }^{13}$ Sign-lang.uni-hamburg.de. EU Project Signing Books. 2015; Available from: https://www.sign-lang.uni-hamburg.de/signingbooks/. measures related to science literacy and procedures of the deaf students were collected[45].

Elghoul introduced a specialized learning content management system (LCMS) that generates multimedia courses to teach and learn SL, allowing teachers to create courses for deaf students without the need to learn SL. This system mainly uses Websign, a web-based interpreter of SL developed for this study, which is a tool that permits the automatically conversion of written texts into visual gestured spatial language using avatar technology[27].

In 2007, a centralized e-learning system for deaf children in Jordan was proposed. This system was implemented for mathematics classes in three Jordanian schools with a view to evaluating whether existing ICT technologies are suitable for introducing interactivity within the classrooms for the deaf. This was assessed through the evaluation of cognitive impact and usability of such a system during teaching activity. Successful application of this system paved the way for the complete support system for the education of deaf pupils in Jordan[46].

Subsequently, in 2010, an accessibility system that offers Arabic Sign Language (ArSL) for the Arabic deaf was presented. This system enables deaf students to access the web for learning processes and presents bilingual information (Arabic text and ArSL) along with high level of visualization and interactive and explorative learning. The use of SL improves the reading competence of deaf persons and enhances their acceptance and understanding of learning content presented to them. This system was used to convert Web-based content to ArSL using an avatar, which adds an extra feature to the education system. This extra feature makes the system adequate to support the accessibility of disabled student. The advantage of this system is that the lecturer does not need special communications skills and the deaf students can view the lecture text in their own language[47].

\section{SURVEYING THE INTEREST OF SAUID DEAF TO STUDY PROGRAMMING}

\section{Deaf high school student survey}

In order to study whether the deaf students in Saudi Arabia are willing to study Computer Programming or not and to sense their readiness to accept such a learning tool, a survey was conducted to seek their responses to the following questions:

\section{Gender}

2. How old are you?

3. How often do you use a computer?

4. How well are you familiar with the following applications? (Word, Excel, PowerPoint\& Access)

5. Do you use the internet?

6. If yes, what are the purpose of using the internet?

7. Are you interested in continuing your higher education?

8. If yes, what is the major you would like to specialize in?

1. How do you prefer to continue your higher education? 
2. Do the following aspects concern you about attending a university?

- I might not have the required assistance

- I might not understand from the tutor without an interpreter

- I would not communicate with the other students

- I might feel lonely and isolated

9. If no, why don't you want to continue your higher education? *Required

- I don't think I would need it

- I am afraid I will be isolated and will feel social execution

- I believe it is going to be difficult

- I would not be supported with the required tools

If there are any other reasons, please specify:

10. If you were provided with the right learning tools that visualize the learning content would you be interested in continuing your higher education?

11. If you were provided with the right learning tools that visualize the learning content and programming output to teach you computer programming, would you like to study it?

12. Which of the following best describe you?

- I like to attend regular classes and I understand better when a tutor teaches me

- I like to study by myself and understand better when I am alone

- Other

Collection of the sample (description of the sample)

The research was conducted on about 47 deaf student participants selected for the purpose of the study. The sample population consisted of all the deaf students at the high school level in Jeddah city, which is the second largest city and economic capital of Saudi Arabia. The study population included both male and female students of different ages, ranging from about 16 years to slightly above 19 years. Therefore, the selection of the population was ideal for this study. The main idea under consideration during the study is to collect any ideas and views that the participants might have regarding their relationship with the virtual environment, specifically in relation to the learning, mainly at tertiary education levels, as deaf students. It is perceived that most of the participants are well acquainted with the technological advancements that create the virtual learning environments such as the use of computers.

The study was backed through a scientific research process. Actual collection of data from the field was made through a questionnaire survey. The questionnaire contained items that inquired into the usage of the computer system in order to determine how fit the learners are, in terms of their preparedness to use computer system in the learning process. Because the learning of computer programming ideally occurs in a virtual environment, the questionnaires were designed such that they allowed assessment of the level of acquaintance of the learners with the system, given that they cannot hear.
This is in respect to computer usage because it is the main source of information in the learning process for the deaf and hearing-impaired students.

The research sample was selected without gender considerations in order to make it appear ideal, since it represents the entire study population. With respect to the need to collect viable data from the survey process, the sampling done mainly tested the familiarity with computers and ability of the learners to use various applications. In addition, the sample population was expected to have knowledge about internet usage as well as have an inclination towards higher education. This is because the research was focused on evaluating the situation regarding improving learning of the deaf and hearing-impaired students within higher institutions of learning. Knowledge about the sample population's preferred professional courses was also mandatory because the research specifically addressed the study of computer programming, given that there are many courses that can use the program. Since this was a random sampling exercise in an effort to collect field data, the sample was ideal in enhancing the research process.

\section{Results AND DisCUSSION}

The information collected from the field was analyzed using charts in order to offer an analysis of the participants' responses with regard to various parameters. The charts provide a rough representation of the ideal situation on the ground in terms of percentages with respect to the virtual learning environment and its significance in promoting learning among the deaf and hard-of-hearing students in Saudi Arabia. The analysis offers a foundation into the analysis of the level of preparedness that the country has to receive the virtual learning system avatars to enhance the learning of deaf students. The results and analysis of the data are discussed in the subsequent paragraphs.

\section{Computer Usage}

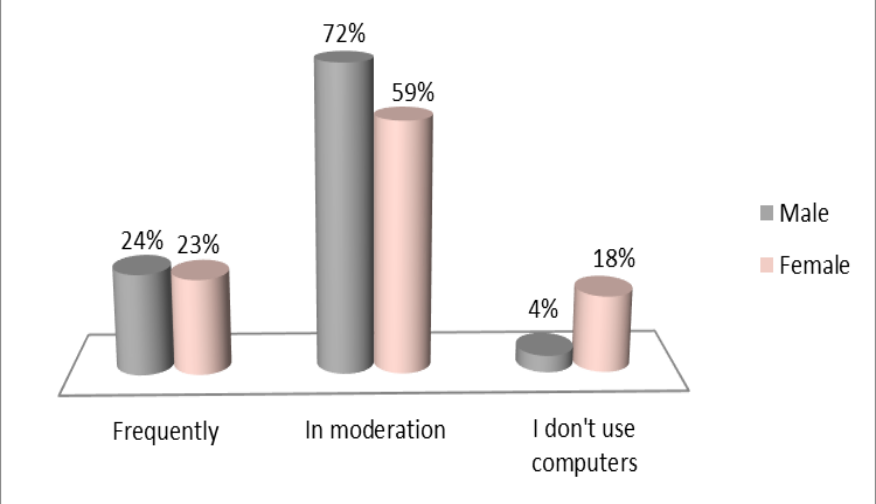

Fig. 1. Computer usage among deaf males and females

The analysis of the respective data collected shows the variations in statistics, depending on the variable under consideration. For instance, as shown in Fig. 1, the majority of both males and female use computers in moderation, while a very small percentage do not use computers at all. 


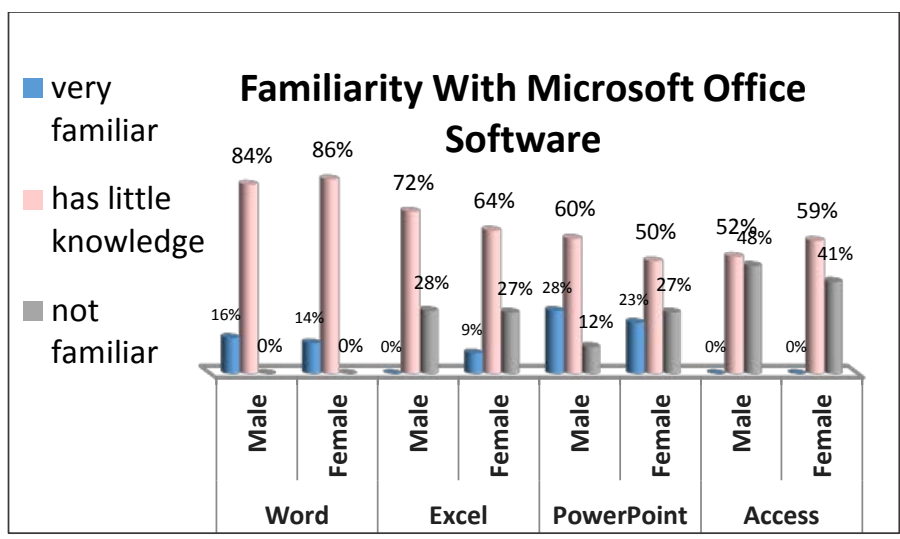

Fig. 2. Familiarity with Microsoft Office Software

In terms of familiarity with Microsoft Office software, the above chart (Fig. 2) shows that a high percentage of the participants had little knowledge about the word processing package. This indicates a relatively high level of computer illiteracy as far as the virtual learning is concerned. It also shows clearly that a significant proportion of the sample population is not farmiliar with the primary packages such as access, excel, and powerpoint. This lack of familiarity can derail the progress of virtual learning in any given country. Despite these shocking statistics, the number of internet users seems to be quite high, with over $96 \%$ of the people responding positively to the use of internet, as shown in Fig. 3.

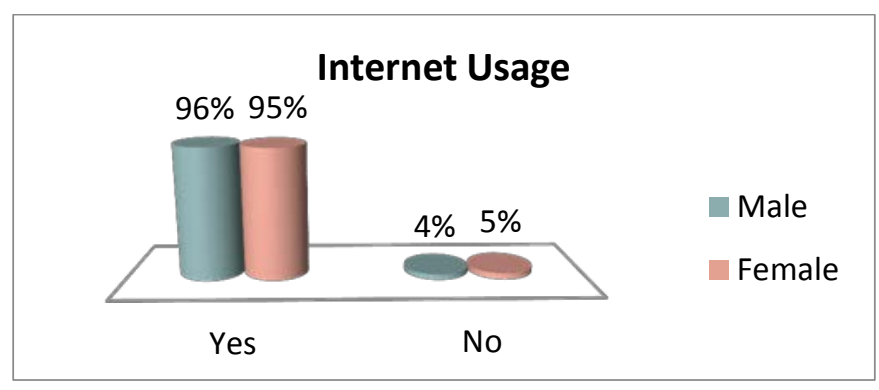

Fig. 3. Internet usage

The responses pertaining to internet usage show that it is evident that a very high percentage of the population actively knows about the internet and uses it. However, in relation to virtual learning, the number of persons who use the internet for studying purposes is very negligible and most of the sample use the internet for social media, as shown in Figure 4.

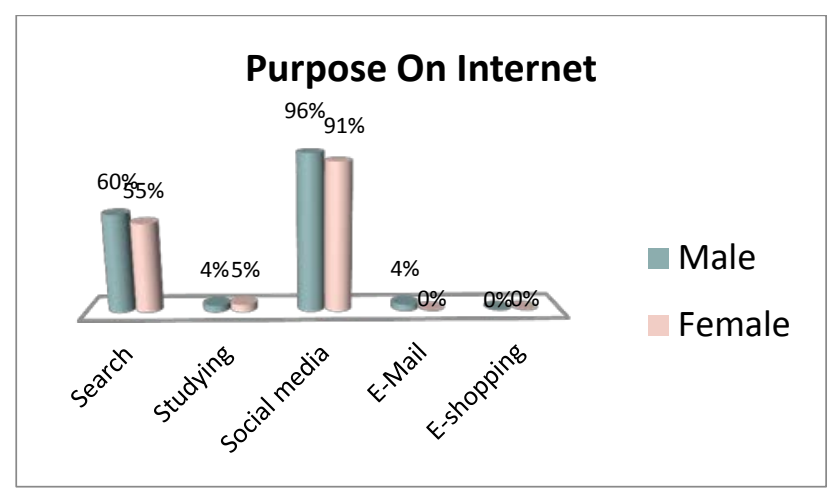

Fig. 4. Purpose of Using Internet
As shown in Figure 5, most of the particiapnts in the study expressed interst in continuing their higher education.

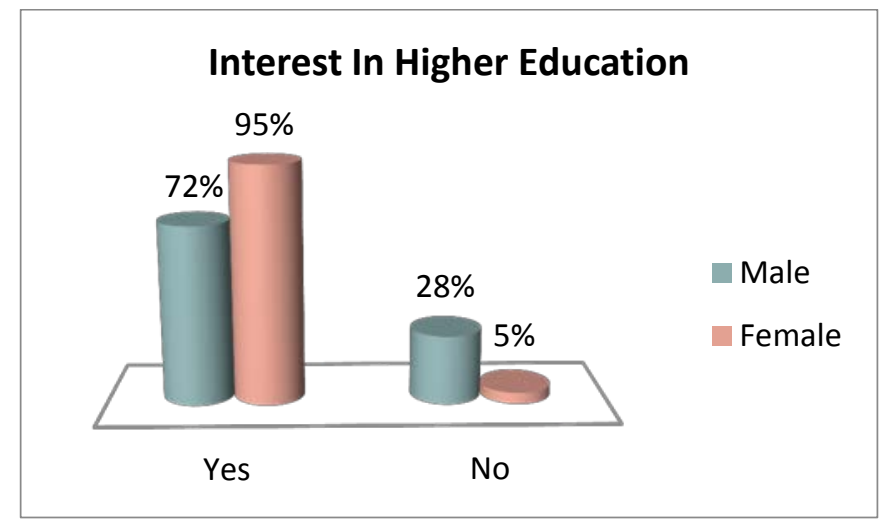

Fig. 5. Interest of Higher Eductation

With respect to the majors in which the sample population expressed interest, (Figure 6) the majority of the participants in the survey were willing to pursue education in computer science.

\section{Interested Majors}
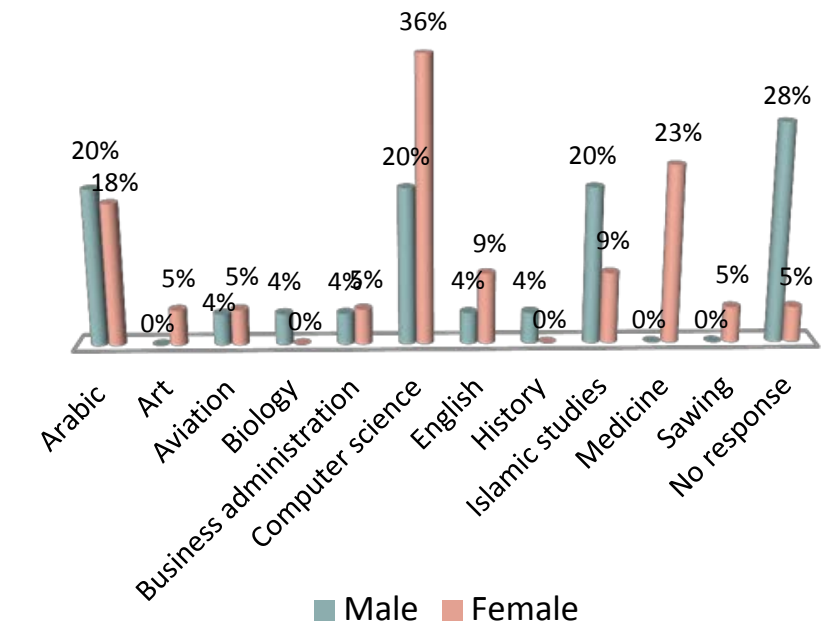

Fig. 6. Majors preferred by sample

However, a good number of persons were also undecided and did not know which would be the best option for them. Possibly, those who chose computer science were willing to immerse themselves in the virtual world, while those who never gave any response did not have any inclinations towards technological subjects. On the other hand, as shown in Figure 7, a good percentage of participants showedtheir willingness to attend and continue with higher eduction in the universities. However, the number of particiapnts willing to undertake the education programmes through a virtual enviroment was very low, probably because it is still a new venture, and more awareness is required among the public regarding this option so that they can readily embrace it as an alternative. 


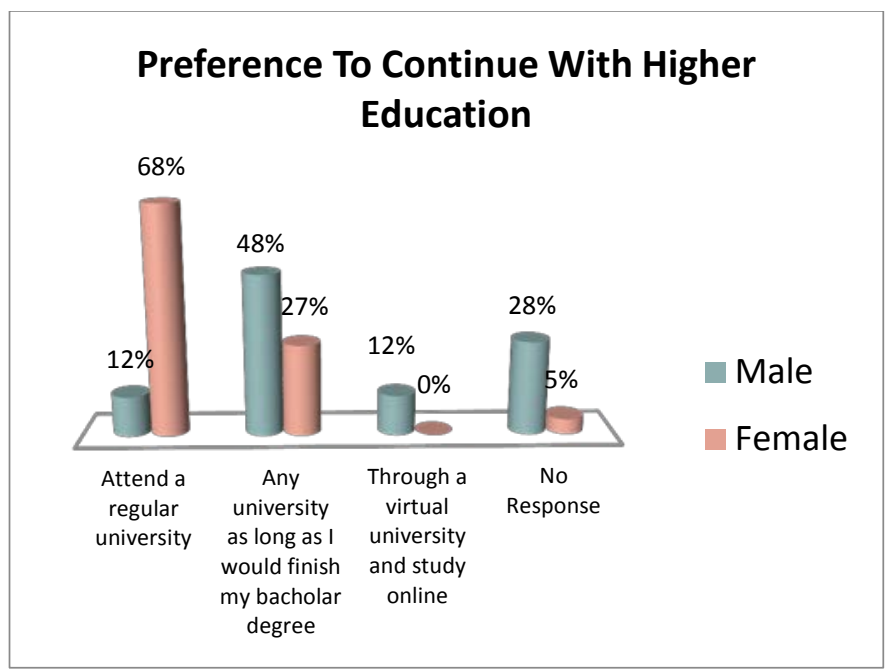

Fig. 7. Preference learning style to continue higher education

\section{Limitations of the experiment}

The research requires adequate information in order to come up with accurate and reliable results. However, due to the time constrains for the research process, the collection of sufficient information becomes difficult and hinders the process of proper inferences and analyses.

Moreover, the respondents of the questionnaires under normal circumstances should be persons unknown to the researcher. This is because familiarity may compromise the quality of the information collected because of personal biases. However, even with the ideal sample research population selected randomly, it is possible that there may be some level of bias, compromising the quality of the research information. This may affect the authenticity of the result findings to some extent.

\section{CONCLUSION}

Deaf students in Jeddah are eager to continue their higher education especially if they are provided with the right tools and more than $95 \%$ of them use the internet and most of them are familiar with various computer applications. If the right tool is implemented more than third of the study population are interested in computer science field or other applied sciences.
Thus, our study shows that the signing avatar tools can automatically convert spoken language into sign language for interpretation by hard-of-hearing and deaf individuals. These tools will pave the way for student learners to access information that is readily available in the instruction language. Since English is a universally accepted language for communication and instruction in most countries, including Saudi Arabia, these tools are expected to be instrumental in promoting higher education among deaf persons within the country.

Some of the currently available systems may be suitable for implementing the signing avatar system and thereby actively contribute to making the system a success in the learning of the deaf in Saudi Arabia. The systems include VisiCast, SignSmith, SignCom, LATLab, and Say It Sign It. These systems have different applications that can aid in distance learning in a virtual learning environment.

In the future, signing avatar systems can possibly replace human personnel by functioning as interpreters. Therefore, the avatar should be capable of executing a number of functions related to the translation of language into other forms understandable by the deaf and hard-of-hearing persons. Efforts should be directed towards developing ways to enhance the viewing of images in a three-dimensional perspective to ensure clarity and quality enhancement. Since the system is not human, users should be keen enough to keep up with the system movements at all times since repetitions may not be made. Further, the quality of the translations made using the avatar systems are of importance in understanding the message communicated. However, it is important to note that prolonged usage of the avatar systems in a single session appears to be monotonous and boring. The signing avatar system is an explicit invention geared towards improving learning for the deaf and hard-of-hearing students, specifically in Saudi Arabia. Although development in the practical application of this system may be slow in pace, it is certain that further advances will lead to the realization of an ideal signing avatar tool to assist in the learning of the hard-ofhearing and deaf persons.

The following infographic provides a better view of the level of the deaf students' interest and knowledge about the usage of computers and internet. It also shows their interest in continuing their higher education and the majors they prefer to study. 


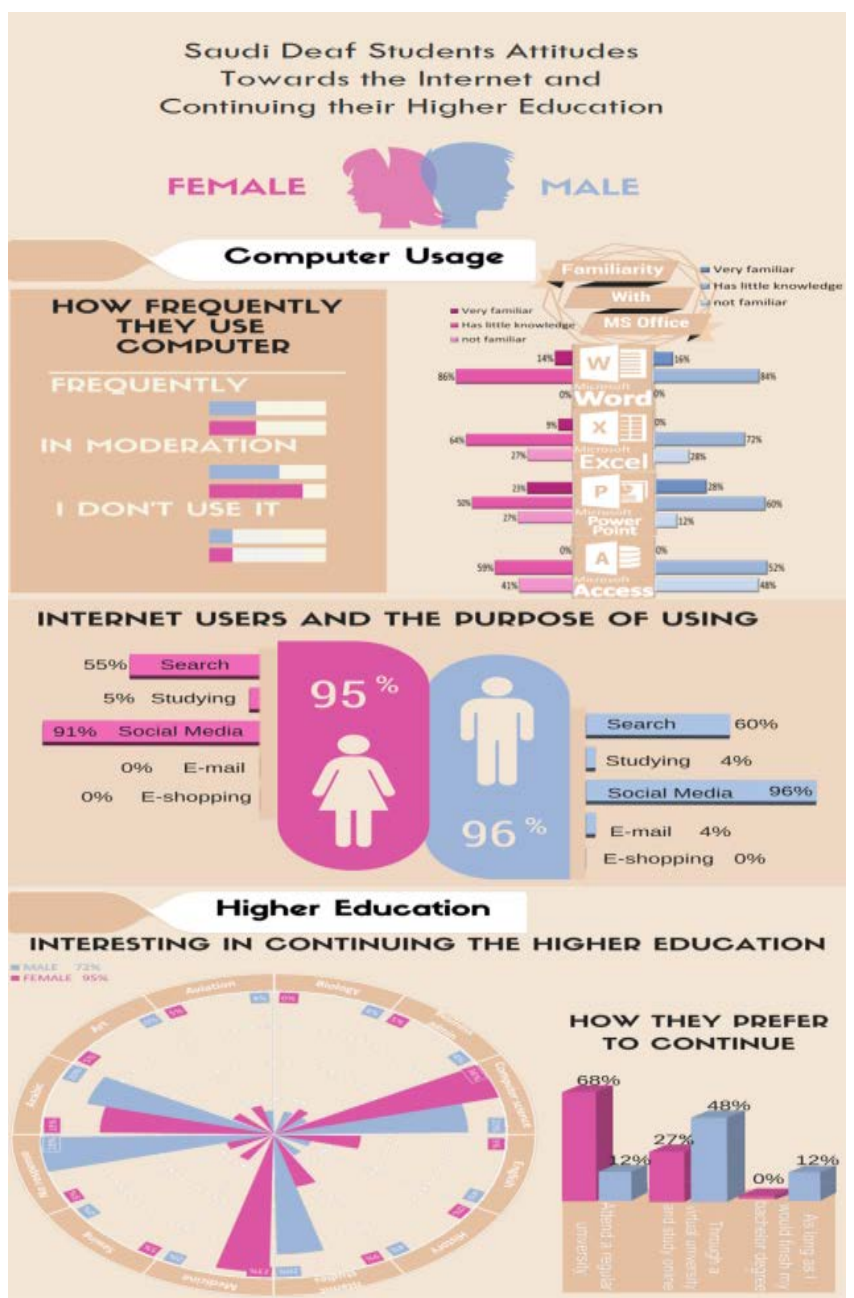

REFERENCES

[1] van Gent, T., et al., Self-concept and ego development in deaf adolescents: a comparative study. Journal of deaf studies and deaf education, 2012. 17(3): p. 333-351.

[2] Andrei, S., L. Osborne, and Z. Smith, Designing an American Sign Language Avatar for Learning Computer Science Concepts for Deaf or Hard-of-Hearing Students and Deaf Interpreters. Journal of Educational Multimedia and Hypermedia, 2013. 22(3): p. 229-242.

[3] COURSE, S.T., ICTS IN EDUCATION FOR PEOPLE WITH SPECIAL NEEDS. 2006.

[4] Goldin-Meadow, S., The resilience of language: What gesture creation in deaf children can tell us about how all children learn language. 2005: Psychology Press.

[5] Bisol, C.A., et al., Deaf students in higher education: reflections on inclusion. Cadernos de Pesquisa, 2010. 40(139): p. 147-172.

[6] Lang, H.G., Higher education for deaf students: Research priorities in the new millennium. Journal of deaf studies and deaf education, 2002. 7(4): p. 267-280.

[7] Boulares, M. and M. Jemni, 3D motion trajectory analysis approach to improve Sign Language 3D-based content recognition. Procedia Computer Science, 2012. 13: p. 133-143.

[8] Faraj, B., W. Alrajhi, and Y. Elhadj, Avatar Based Approach for Teaching Arabic Sign Language Journal of Communications and Computer Engineering 2011. 2.2: p. 43-48.

[9] Wareham, T., G. Clark, and C. Laugesen, Providing learning support for $\mathrm{d} /$ Deaf and hearing-impaired students undertaking fieldwork and related activities. 2001.

[10] Organization, W.H., WHO Global Estimates on Prevalence of Hearing Loss. Geneva: WHO, . 2012.
[11] Mitchell, R.E., How many deaf people are there in the United States? Estimates from the Survey of Income and Program Participation. Journal of deaf studies and deaf education, 2006. 11(1): p. 112-119.

[12] Daghistani, K.J., T.S. Jamal, and S.M. Zakzouk, The management of hearing impaired Saudi children: An epidemiological survey. Bahrain Medical Bulletin, 2002. 24(1): p. 7-12.

[13] Hamrick, S., et al., LibGuides. Deaf Statistics. Asia, the Middle East, and Oceania. 2010.

[14] Secretariat, G., Global Survey Report WFD Regional Secretariat for Mexico, Central America and the Caribbean Global Education PrePlanning Project on the Human Rights of Deaf People Compiled by Mr Colin Allen Project Co-ordinator. 2008.

[15] Education, S.M.o. Education Statistic System. 2015; Available from: https://hesc.mohe.gov.sa/pages/default.aspx.

[16] Erting, C.J., et al. The deaf way. in Perspectives from the international conference on deaf culture. Washington DC. 1994.

[17] Youssif, A.A., A.E. Aboutabl, and H.H. Ali, Arabic sign language (arsl) recognition system using hmm. International Journal of Advanced Computer Science and Applications (IJACSA), 2011. 2(11).

[18] Ebbinghaus, H. and J. Heßmann, Signs and words: Accounting for spoken language elements in German Sign Language. International review of sign linguistics, 1996. 1(1): p. 23-56.

[19] Armstrong, D.F., Show of hands: a natural history of sign language. 2011: Gallaudet University Press.

[20] Sandler, W. and D. Lillo-Martin, Natural sign languages. Handbook of linguistics, 2001: p. 533-562.

[21] Cox, S., et al. Tessa, a system to aid communication with deaf people. in Proceedings of the fifth international ACM conference on Assistive technologies. 2002. ACM.

[22] Blake, E., W. Tucker, and M. Glaser, Towards communication and information access for Deaf people. 2014.

[23] Debevc, M., Z. Stjepanovič, and A. Holzinger, Development and evaluation of an e-learning course for deaf and hard of hearing based on the advanced Adapted Pedagogical Index method. Interactive learning environments, 2014. 22(1): p. 35-50.

[24] Cooper, H., B. Holt, and R. Bowden, Sign language recognition, in Visual Analysis of Humans. 2011, Springer. p. 539-562.

[25] Al-Jarrah, O. and A. Halawani, Recognition of gestures in Arabic sign language using neuro-fuzzy systems. Artificial Intelligence, 2001. 133(1): p. 117-138.

[26] ELGHOUL, M.J.O., An avatar based approach for automatic interpretation of text to Sign language. Challenges for Assistive Technology: AAATE 07, 2007. 20: p. 266.

[27] ElGhoul, O. and M. Jemni. WebSign: A system to make and interpret signs using 3D Avatars. in Proceedings of the Second International Workshop on Sign Language Translation and Avatar Technology (SLTAT), Dundee, UK. 2011.

[28] Al-Nafjan, A. and Y. Al-Ohali. A Multimedia System for Learning Arabic Sign Language: Tawasoul. in E-Learn: World Conference on ELearning in Corporate, Government, Healthcare, and Higher Education. 2010.

[29] Adamo-Villani, N., E. Carpenter, and L. Arns. An immersive virtual environment for learning sign language mathematics. in ACM SIGGRAPH 2006 Educators program. 2006. ACM.

[30] Dean, R.K. and R.Q. Pollard, Application of demand-control theory to sign language interpreting: Implications for stress and interpreter training. Journal of deaf studies and deaf education, 2001. 6(1): p. 1-14.

[31] Mishra, M., V.K. Sharma, and R. Tripathi, ICT as a Tool for Teaching and Learning in Respect of Learner with Disability. 2015.

[32] Blurton, C., New directions of ICT-use in education. Retrieved on, 1999. 24: p. 2012.

[33] Kulik, J.A., Effects of using instructional technology in elementary and secondary schools: What controlled evaluation studies say. 2003: Citeseer.

[34] Drigas, A., et al. An e-Learning System for the Deaf people. in 2005 6th International Conference on Information Technology Based Higher Education and Training. 2005. IEEE. 
[35] Liu, C.-f., Academic and Social Adjustment among Deaf and Hard of Hearing College Students in Taiwan. 2013.

[36] Lang, H., et al., Learning styles of deaf college students and instructors' teaching emphases. Journal of Deaf Studies and Deaf Education, 1999. 4(1): p. 16-27.

[37] Convertino, C.M., et al., Predicting academic success among deaf college students. Journal of deaf studies and deaf education, 2009: p. enp005.

[38] Cheng, S., L.-F. Zhang, and X. Hu, Thinking styles and university selfefficacy among deaf, hard-of-hearing, and hearing students. Journal of deaf studies and deaf education, 2015: p. env032.

[39] Straetz, K., et al. An e-learning environment for deaf adults. in Conference proceedings 8th ERCIM workshop "user interfaces for all. 2004.

[40] Kipp, M., et al. Assessing the deaf user perspective on sign language avatars. in The proceedings of the 13th international ACM SIGACCESS conference on Computers and accessibility. 2011. ACM.

[41] Ghanem, S.F. and I. Albidewi, An Avatar Based Natural Arabic Sign Language Generation System for Deaf People. 2008, M. Sc. Thesis,
King Abdulaziz University, Jeddah, Saudi Arabia.

[42] Stoyanov, S. and N. Stoyanova. SMILE: Intelligent Learning Environment Accumulating Personal Styles of Users. in WebNet World Conference on the WWW and Internet. 2000.

[43] Smith, R., S. Morrissey, and H. Somers, HCI for the Deaf community: Developing human-like avatars for sign language synthesis. 2010.

[44] Halawani, S.M., D. Daman, and S. Kari, An Avatar Based Translation System from Arabic Speech to Arabic Sign Language for Deaf People. International Journal of Computer Science and Network Security (IJCSNS), 2013. 13(12): p. 43.

[45] Lang, H.G. and D. Steely, Web-based science instruction for deaf students: What research says to the teacher. Instructional Science, 2003. 31(4-5): p. 277-298.

[46] Khwaldeh, S., N. Matar, and Z. Hunaiti, Interactivity in deaf classroom using centralised E-learning system in Jordan. PGNet, ISBN, 2007: p. 19025.

[47] El-Soud, M.A., et al., A proposed web based framework e-learning and dictionary system for deaf Arab students. IJECS, 2010. 2828: p. 106401. 